to describe what has already passed between patient and staff (unless something striking or unusual has happened) may only encourage an undesirably rigid idea that the problem has been dealt with.

Medical social workers and others, seeing a patient for the first time after being informed that he knows his diagnosis and prognosis, are often puzzled to find that this does not appear to be the case. The cause is twofold. Firstly, when doctors talk of "telling" or "not telling" the patient, they differ considerably as to what they mean by these phrases. Many British doctors, for example, believe that in the United States "they tell all their patients." Yet it was recently claimed in an American medical journal that $90 \%$ of American doctors "usually do not tell." 15 Secondly, the denial mechanism and a preference for euphemisms may have already come into play, and perhaps the patient totally suppresses part of what was said to him and emohasises another part.

Sometimes it is suggested that the best solution to this problem is to leave all such discussion to the family doctor, who probably knows the patient, his family, and his responsibilities better. But there are serious objections to this. Firstly, the specialist has first-hand knowledge of all the benefits and side effects experienced by many other patients in a similar situation. The patient senses this and realises that he is not just getting a second-hand opinion or a view based on a fairly small experience of his particular problem. Secondly, to delay until the patient sees his own doctor can cause unacceptable anxiety. Thirdly, the hospital doctor, particularly if he specialises in cancer, has a far better chance than the family doctor of being able to provide valuable encouragement by telling of a similar patient who responded well to treatment; perhaps of one who recently attended for a checkup, who is back at work and enjoying life. A specialist in a large centre, unlike the family doctor, may refer to such cases without risk of breach of confidence.

\section{Conclusion}

"It is fear that I stand most in fear of," wrote Montaigne nearly 400 years ago, "in sharpness it exceeds every other feeling." So we must try to relieve this particular form of suffering, just as we try to relieve pain; and good communication can often do this better than any drug. We must communicate both efficiency and kindness; and we must not confuse diagnosis with prognosis. Whatever the outlook, our main objective is to maintain morale and to help the patient to achieve maximum courage, equanimity, and peace of mind, but not in a shortsighted way which will create difficulties later on. Most of us prefer to be pragmatic, in the best sense of the word, rather than to follow some set dogma; to assess as best we can (preferably with the help of relatives and nursing staff) the immediate and late effects of what we have said or not said, modifying accordingly our future policy in similar circumstances; and trying to learn from our mistakes, just as we do in any other aspect of patient care.

Central to the art of good communication is firstly to try to get the amount of information and explanation about right. Lack of information can greatly increase anxiety and stress (knowledge is the antidote to fear, said Emerson)-but so can too much of it. Secondly, whether the outlook is good or bad, to give appropriate reassurance and encouragement. There is always something to reassure the patient about and nearly always something to be positive and optimistic about, even if this is only the prospect of symptom relief. Thirdly, to be watchful and flexible, especially if there is a change (as there often is) either in the prognosis, in the patient's attitude, or in his threshold for anxiety and depression. And finally-sometimes directly in serious conversation, sometimes indirectly, by word or by manner, by humour or by friendship-to remind the patient whose outlook is serious, but not hopeless, that few things in this world are certain and that the difference between the uncertainties that he faces and those faced by others his age may be only a matter of degree. We are all travelling the same road.

\section{References}

${ }^{1}$ Saunders, C M, in Scientific Foundations of Oncology, ed T Symington, p 673. London, Heinemann, 1976.

${ }^{2}$ Brewin, T B, in Cancer Priorities. London, British Cancer Council, 1971.

3 Hutchison, R, British Medical fournal, 1928, 1, 335.

4 Abrams, R, New England fournal of Medicine, 1966, 274, 317.

5 Aldrich, C K, Fournal of the American Medical Association, 1963, 184, 329.

${ }^{6}$ Barber, H, The Practitioner, 1948, 161, 76.

${ }^{7}$ McIntosh, J, Lancet, 1976, 2, 300.

${ }^{8}$ Chesser, E S, and Anderson, J L, Proceedings of the Royal Society of Medicine, 1975, 68, 793

${ }^{9}$ Witzel, L, British Medical fournal, 1975, 2, 81.

${ }_{10}$ Aitken-Swan, J, and Easson, E C, British Medical fournal, 1959, 1, 779.

${ }^{11}$ Hinton, J, British Medical Fournal, 1974, 3, 25.

12 Cartwright, A, Hockey, L, and Anderson, J L, Life Before Death. London, Routledge and Kegan Paul, 1973.

${ }^{13}$ Kubler-Ross, E, On Death and Dying. London, Tavistock Publications, 1970.

14 Holmes, O W, The Professor at the Breakfast Table. Boston, 1859.

15 Schneiderman, L J, New England fournal of Medicine, 1977, 216, 825.

\title{
What is the monetary value of a human life?
}

\author{
W I CARD, G H MOONEY
}

British Medical fournal, 1977, 2, 1627-1629

\section{Summary}

The resources available to the health service are limited and so the amount the NHS can spend on saving human life is also limited. Rational allocation of resources

\footnotetext{
University Department of Medicine, Western Infirmary, Glasgow G11
}

W I CARD, MD, FRCP, senior research fellow

Health Economics Research Unit, Department of Community Medicine, University of Aberdeen, Aberdeen AB9 2ZD

G H MOONEY, MA, director requires a decision theory model, which in turn demands some monetary valuation of human life. Each of three approaches discussed-basing value on productive capacity, the NHS's implied values, or individuals' values-rests on an underlying set of non-monetary values. Choice of the underlying value will determine the method to be used in placing a monetary value on life. As the Health Service implicitly places certain values on life already, a means of making this valuation more rational and explicit can only improve the quality and quantity of health care.

\section{Introduction}

Even in the early days of the NHS it was recognised that a comprehensive health service could not be provided for every 
citizen. In 1952 Roberts wrote: "The task will be to determine how our limited resources can be put to the best use." This problem is now widely recognised, and even if extra resources were to be made available to the Health Service choices would still have to be made against a background of some needs being unmet.

In deciding what types of health care to provide value judgments inevitably have to be made. Should we save more lives, provide greater care for the elderly, increase prevention, improve the quality of nursing, increase patient satisfaction, shift the balance of care ? To make such decisions judgments are required on the relative benefits associated with the different outcomes of the health care system.

This requires a decision theory model, in which we need to know the monetary value of various outcomes (utilities), the probability that these outcomes will occur from a particular course of action, and the cost of the course of action.

The most contentious aspect is assessing the utilities-putting a monetary value on the outcome. In this paper we are primarily concerned with the ways of valuing human life, and the sets of values that underlie these judgments.

\section{Decision theory}

To analyse the problem formally in terms of decision theory we have chosen a simple example. (For an introduction to decision theory see Lindley. ${ }^{2}$ )

Let us suppose that a doctor is faced with a choice of treatments $T_{1}$ and $T_{2}$ and suppose that for each there are two definable outcomes, $\mathrm{O}_{1}$ and $\mathrm{O}_{2}$ (see fig). A numerical measure

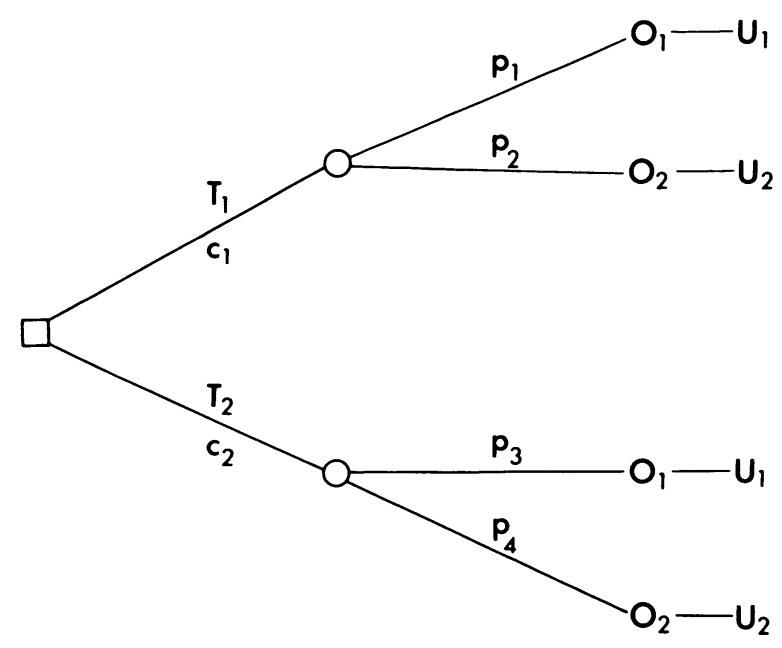

Decision tree with two treatments and two outcomes.

of value has to be attached to each of these outcomes; the technical word for this value is utility, $U_{1}$ and $U_{2}$. But a given treatment is not followed by a given outcome with certainty but only with a degree of probability, so probabilities have to be attached to each outcome $-p_{1}$ and $p_{2}$, and $p_{3}$ and $p_{4}$. The value of a treatment, $T_{1}$, is on average $p_{1} U_{1}+p_{2} U_{2}$, and this is called its expected utility. But the treatment also carries a cost, $c_{1}$ and $c_{2}$, which covers not only monetary cost but also any pain, anxiety, and danger to life. These costs have to be subtracted from the expected utility of the treatment. The best treatment is therefore the one that, after deduction of the costs, has the greatest expected utility. In medicine, where there is a large degree of uncertainty, this may be called the best bet. But this analysis forces us to express the measure of utility and cost in the same units, and this means that monetary values have to be found for the outcomes of health care, one of which is, of course, the saving of human life.

\section{Measuring utilities}

One way of obtaining the utilities attached to different health outcomes is to study the decision maker's consistency of choice in real or simulated situations to determine his implicit utilities. ${ }^{3}$ The principle has been applied to estimating the utilities of states of health with different visual acuities. ${ }^{4}$ These may, however, be thought of as one-dimensional. The states of health commonly encountered are multidimensional, and here the problem of estimating utilities is unsolved.

The value system underlying a judgment about the monetary value of human life is a social one and not solely a medical one. As Dunstan has said: "This question is not, as is so commonly supposed, a question of personal and professional ethics only, as the doctor's question; it is society's question also, one of social ethics, upon which the whole community has to make up its mind, if the possibilities of medical practice . . . are to yield their potential for the common good.";

\section{Why we should measure utilities}

The suggestion of putting a monetary value on human life may at first sight seem repulsive. Life, it is often said, is priceless; but this belief springs from a misunderstanding and depends on who is making the judgment. If someone we loved was kidnapped and if we had won $£ 100000$ on the pools we should be prepared to hand over all this money to save a life. But the Health Service, with its limited resources of some $£ 5.4$ billion a year and its responsibility for the health care of 55 million people, cannot value a life at this figure. The monetary value of human life is therefore a notional one that is introduced to secure coherence in the range of decisions that have to be made in the NHS. A recent book ${ }^{6}$ that explores the application of decision theory to surgical practice largely evades this problem of estimation, however. One of the contributors says: "The reduction to dollar figures of inherently non-quantifiable entities such as death ... pain, and suffering forms the greatest barrier to the implementation of these methods." ?

If we could estimate both the costs and utilities in monetary terms not only could we suggest the best treatment but we could also calculate whether an expensive diagnostic test was "worth while." The results of failure to apply simple arithmetic to the cost of diagnostic tests are well illustrated by Neuhauser and Lewicki. ${ }^{8}$ They noted that the American Cancer Society had endorsed a protocol of six sequential tests of stool for occult blood to exclude cancer of the large bowel. They calculated, making certain assumptions, that the cost per case detected by the sixth test was $\$ 47 \mathrm{~m}$.

The important consideration is not that the NHS cannot afford financially to spend more than some amount on saving life but that it cannot afford in health terms to spend too much on saving life. The price of saving life in one way is the potential loss of other health benefits (including saving life in other ways).

\section{Methods of estimation}

We describe here three approaches to the valuation of human life. How one chooses between them depends very much on the value system on which the Health Service is assumed to rest.

\section{PRODUCTIVE CAPACITY}

Economists have been concerned with the question of valuing life at least since the 17 th century, when Sir William Petty designed a method of evaluation that was based on the assumption that an individual contributes to society (and himself) by his production, which is equated with his earnings. ${ }^{9}$ This earnings estimate, discounted to its present value and adjusted for likely participation in the work force, expectation of working life, etc, provides one means of calculating the value of human life, ${ }^{10-12}$ and is still one of the most commonly used methods. The Department of Transport, for example, in assessing road 
safety policies, used this approach to estimate that the value of life is $£ 39000$.

This method has two main weaknesses. Firstly, it takes no account of either the existing decision-making processes in the Health Service or the views of the individual patients at risk. Secondly, it implies that the objective of health care is to add to the productive capacity of the nation, which is true but it is not the sole objective.

\section{GENERAL IMPLICIT VALUES}

Through its existing decision-making processes the Health Service already implicitly places values on life, although these values are seldom made explicit. For example, a decision may be made not to devote resources to some life-saving policy, which implies that the benefits of saving life are less than the costs of doing so, thus putting a ceiling on the value of life.

An examination of past decisions (see table) is likely to yield a fairly wide range of implied values of life distributed about some mean. As a first approximation the mean implied value could be used as the value of life in health care. Areas that yielded values above the mean might then be deemed areas of overinvestment. Where the values were below the mean these might be seen as areas ripe for increased investment.

But there is no reason to believe that the mean implied value of life is in any sense "correct," particularly as regards the implied values placed on other aspects of health care-for example, reduced morbidity. Furthermore, the value might vary for several reasons, such as age and the quality of life of the lives saved. Consequently the Health Service should not adopt $a$ value for life, but calculating a mean implied value might help in that it would demand that departures from the mean should be justified.

The study and use of implied values might increase consistency and efficiency in health care decision making. Thus if the existing decision-making process is deemed optimal and the Health Service, with its underlying medicopolitical value system, is made responsible for judgments about priorities within health care then the implied value approach can be defended.

\section{INDIVIDUALS' VALUES}

Since society as a whole has an interest in health, it may be argued that it is the individuals who comprise society who should determine the values to be used.

At any time the risk of death associated with particular lifethreatening circumstances for a given individual is usually very small. For such an individual the appropriate question is not: What is the value of your life ? but What value would you place on reducing your risk of death from $\mathrm{x}$ to $\mathrm{y}$ ? (where $\mathrm{x}$ and $\mathrm{y}$ will be closer to zero than to one).

It would be very difficult to obtain such information and some may deny that it is relevant to ask individuals to form such judgments. In some circumstances, however, a study of individuals' behaviour may provide implied values of life or of reduced risk-for example, whether people fitted seat belts in cars before this was made compulsory. The alternative is to question people directly, as has been done by Jones-Lee. ${ }^{13}$ Individuals were asked to make choices between competing airlines, where the only differences were that one airline was safer and more expensive than the other. By varying the differential risk levels and the differential in fares it was possible to determine how much the individual was prepared to pay for a given increase in safety. This approach is still at a developmental stage.

\section{UNDERLYING VALUES}

Which of these three types of approaches is adopted is in itself a value judgment and depends on the value system on which it is considered the Health Service rests. Is it relevant to use
Values of life inferred from several public policy decisions*

\begin{tabular}{|c|c|c|}
\hline Decision & $\begin{array}{l}\text { Implied value } \\
\text { of life }\end{array}$ & Comment and source \\
\hline $\begin{array}{l}\text { Screening of } \\
\text { pregnant } \\
\text { women to } \\
\text { prevent } \\
\text { stillbirths }\end{array}$ & $£ 50$ maximum & $\begin{array}{l}\text { In } 1968 \text { it was estimated that if maternal } \\
\text { oestriol concentrations were screened the } \\
\text { cost per stillbirth averted would be } £ 50 \text {. } \\
\text { It has been claimed that at that time this } \\
\text { procedure was not widely used, which } \\
\text { is why the figure is assumed to be a } \\
\text { maximum value. } \text {. }^{15}\end{array}$ \\
\hline $\begin{array}{l}\text { Not to introduce } \\
\text { child-proof } \\
\text { drug containers }\end{array}$ & $£ 1000$ maximum & $\begin{array}{l}\text { In } 1971 \text { the Government decided not to } \\
\text { proceed with the child-proofing of drug } \\
\text { containers. Allowing for the cost of drug- } \\
\text { proofing and savings to NHS from } \\
\text { reduced admissions, Gould calculated } \\
\text { that a child's life was implicitly valued at } \\
\text { under } \oint_{1000} \text {. }\end{array}$ \\
\hline $\begin{array}{l}\text { Legislation on } \\
\text { tractor cabs }\end{array}$ & $\begin{array}{l}£ 100000 \\
\text { minimum }\end{array}$ & $\begin{array}{l}\text { In } 1969 \text { the fitting of cabs to farm tractors, } \\
\text { to reduce the mortality risk for drivers, } \\
\text { was made compulsory. The cost per } \\
\text { annum was estimated at } f 4 m \text { ( } £ 40 \text { for } \\
\text { each of } 100 \text { o00 tractors). About } 40 \text { lives } \\
\text { would be saved yearly; the implied value } \\
\text { of life was thus } £ 100000 .{ }^{17}\end{array}$ \\
\hline $\begin{array}{l}\text { Changes in } \\
\text { building } \\
\text { regulations as a } \\
\text { result of partial } \\
\text { collapse of } \\
\text { Ronan Point } \\
\text { high-rise flats }\end{array}$ & $\begin{array}{l}£ 20000000 \\
\text { minimum or } \\
\text { perhaps } \\
\text { actual }\end{array}$ & $\begin{array}{l}\text { After a high-rise block of flats partially } \\
\text { collapsed, killing some residents, the } \\
\text { report of the inquiry recommended } \\
\text { changes in the building standards of such } \\
\text { blocks. It has been estimated from the } \\
\text { change in risk and the costs involved } \\
\text { that the implied value of life was } £ 20 \mathrm{~m} .^{8}\end{array}$ \\
\hline
\end{tabular}

*The table includes examples from policy areas other than health care. There are thus two issues raised: $(a)$ the deployment of resources to saving life within health care; and $(b)$ the deployment of public expenditure generally to saving life.

a measure of productive capacity to value health output? Should the judgments be made by the Health Service ? Or should the individuals in society at large determine the values used? An answer to these questions will determine which of the three approaches is adopted. (For a fuller critique of methods of valuing life, see Mooney. $\left.{ }^{14}\right)$

\section{Conclusion}

There is no way of avoiding the fact that, given scarce resources there is a finite limit to the value of life in health care. By implication at least this is already accepted in current dayto-day decision-making within the Health Service. But the valuation of human life should be made more rational and explicit. There is nothing inhumane in this. By doing so the quality and quantity of health care is likely to be increased, and the onus is on those who remain unconvinced to put forward an alternative scheme.

\section{References}

${ }^{1}$ Roberts, F, The Cost of Health. London, Turnstile Press, 1952.

2 Lindley, D V, Making Decisions. London, Wiley Interscience, 1971.

${ }^{3}$ Card, W I, and Good, I J, Mathematical Biosciences, 1970, 6, 45.

${ }^{4}$ Card, W I, et al, Methods of Information in Medicine, 1977, 16, 168.

${ }^{5}$ Dunstan, G R, Proceedings of the Royal Society of Medicine, 1967, 60, 1240.

${ }^{6}$ Bunker, J P, Barnes, B A, and Mosteller, F (editors), Costs, Risks and Benefits of Surgery. New York, Oxford University Press, 1977.

' Green, J R, in Costs, Risks, and Benefits of Surgery. New York, Oxford University Press, 1977.

${ }^{8}$ Neuhauser, D, and Lewicki, A M, The New England fournal of Medicine, 1975, 293, 227.

9 Petty, W, Political Arithmetic. London, Robert Clavel, 1699.

10 Dublin, L I, and Lotka, A J, The Money Value of a Man. New York, Ronald Press, 1946.

11 Weisbrod, B A, Economics of Public Health. Philadelphia, University of Pennsylvania Press, 1961.

12. Dawson, R F F, Current Costs of Road Accidents in Great Britain. London, Road Research Laboratory, 1971

13 Jones-Lee, M W, The Value of Life, An Economic Analysis. London, Martin Robertson, 1976.

${ }^{14}$ Mooney, G H, The Valuation of Human Life. Basingstoke, Macmillan, 1977.

${ }^{15}$ Leach, G, The Biocrats. Harmondsworth, Penguin, 1972

${ }^{16}$ Gould, D, New Scientist, 1971, 51, 217.

17 Sinclair, C, New Scientist, 1969, 44, 120.

18 Sinclair, C, et al, Human Life and Safety in Relation to Technical Change. Science Policy Research Unit, University of Sussex, 1972. 